Jurnal Ilmu Sosial dan Pendidikan (JISIP)

Vol. 5 No. 3 Juli 2021

Terakreditasi Peringkat 5 (No. SK: 85/M/KPT/2020)

e-ISSN : 2656-6753, p-ISSN: 2598-9944

DOI: 10.36312/jisip.v5i3.2244 /http://ejournal.mandalanursa.org/index.php/JISIP/index

\title{
Pengembangan Multimedia Interaktif Biologi Berbasis Savi (Somatic, Auditory, Visual, Intelectual) Pada Materi Monera Kelas X IPA
}

\author{
${ }^{1}$ Syamsul Jum'ah, ${ }^{2 *}$ Maya Ekaningtias \\ ${ }^{12}$ Program Studi Pendidikan Biologi FKIP UNW Mataram \\ Email: ${ }^{1}$ syamsuljumah47@gmail.com; ${ }^{2 *}$ mentias4life@gmail.com
}

\section{Article Info}

Article history:

Article Reseived : 22 July 2021

Publication: 23 July 2021

\section{Kata Kunci:}

Pengembangan, Multimedia

Interaktif, Savi, Monera

\section{Article Info}

Article history:

Article Reseived : 22 July 2021

Publication: 23 July 2021

Keyword

Development, Interactive

Multimedia, Savi, Monera

Corresponding Author:

\begin{abstract}
Abstrak
Penelitian ini bertujuan untuk: (1) menghasilkan media pembelajaran multimedia interaktif biologi berbasis SAVI (Somatic, Auditory, Visual, Intelectual) materi pembelajaran monera; (2) mengetahui tingkat kelayakan multimedia interaktif biologi berbasis SAVI yang telah dikembangkan. Pengembangan multimedia interaktif biologi berbasis SAVI ini mengacu pada model ADDIE. Penelitian ini hanya menggunakan 3 tahap pengembangan yaitu analysis, design, dan develop. Hasil validasi menunjukkan bahwa media pembelajaran multimedia interaktif biologi berbasis SAVI sangat layak digunakan pada materi pembelajaran monera.
\end{abstract}

\begin{abstract}
The objectives of this study were: (1) to produce of interactive multimedia learning media based on SAVI (Somatic, Auditory, Visual, Intelectual) for teaching materials of monera, and (2) to determine the advisability of the learning media. The learning media developed using the ADDIE model. But, this study only used three steps, which were define, design, develop steps. The result of validation scores showed that the interactive multimedia learning media based on SAVI (Somatic, Auditory, Visual, Intelectual) of monera materials was very advisible to be used.
\end{abstract}

\section{Maya Ekaningtias}

Program Studi Pendidikan Biologi FKIP UNW Mataram

Email:mentias4life@gmail.com

\section{PENDAHULUAN}

Multimedia interaktif saat ini mengalami perkembangan yang sangat pesat dalam dunia pendidikan dan memiliki peran penting. Menurut Susilana (2009) penggunaan multimedia interaktif dalam pembelajaran bertujuan untuk mempermudah dan memperjelas penyajian pesan agar tidak terlalu bersifat verbalistis. Multimedia mengkombinasikan teks, suara, gambar, animasi, video yang disampaikan dengan komputer dan dapat secara interaktif. Dengan menggunakan multimedia interaktif akan mencakup semua indra tubuh kita baik secara somatic, auditory, visual, intelectual ( SAVI). 
Pendekatan SAVI adalah proses belajar siswa yang menggabungkan gerakan fisik dengan aktivitas intelektual dan penggunaan semua indra yang dapat berpengaruh besar pada pembelajaran. Pendekatan SAVI menggabungkan 4 (empat) komponen yang berpengaruh pada pembelajaran di kelas. Keempat proses cara belajar ini harus ada agar belajar berlangsung optimal. Istilah SAVI adalah singkatan dari somatic (S) yang bermakna gerakan, auditory (A) bermakna bahwa belajar dengan mendengarkan, visual (V) bermakna belajar menggunakan indra mata, Intelectual (I) bermakna bahwa belajar menggunakan kemampuan berfikir (Wijaya, 2016).

Berdasarakan hasil observasi yang telah dilakukan di MA MU”ALLIMIN NW ANJANI, peneliti menemukan suatu permasalahan yakni pembelajaran yang masih monoton dan bersifat abstrak, sehingga pemahaman siswa dalam suatu ilmu pengetahuan khususnya pembelajaran IPA mengalami titik jenuh bagi semua siswa, terlebih materi Biologi disebabkan banyaknya namanama ilmiah yang harus dihafalkan siswa dan suasana belajar yang cenderung membosankan. Oleh karena itu, pelajaran IPA harus dibuat lebih menarik dan dengan menggunakan media yang tepat, seperti media pembelajaran agar materi yang di sampaikan mudah dipahami.

Tujuan penelitian adalah untuk mengetahui tingkat kelayakan produk pengembangan multimedia interaktif biologi berbasis SAVI Pada Materi Monera Kelas X IPA MA MU'ALLIMIN NW Anjani Tahun Ajaran 2020/2021 menggunakan model ADDIE.

\section{METODE PENELITIAN}

Penelitian ini merupakan jenis penelitian dan pengembangan atau Research and Development (R\&D) yang berorientasi pada produk dan bertujuan untuk mengembangkan multimedia interaktif pada pembelajaran biologi untuk siswa. Pengembangan multimedia interaktif berbasis SAVI yang dikembangkan diadopsi dari model pengembangan ADDIE, terdiri dari tahap analysis, design, develop, implmentation, dan evaluation. Dalam penelitian ini subjeknya adalah siswa kelas X IPA MA MU'ALLIMIN NW Anjani Tahun Ajaran 2020/2021. Objeknya adalah tingkat kelayakan produk berbasis SAVI (somatic, auditory, visual, intelectual). Kondisi pandemik COVID-19 yang membatasi penyelenggaraan pembelajaran tatap muka di sekolah, sehingga tahap pengembangan model ADDIE hanya dilakukan sampai pada tahap develop. Berikut penjelasan mengenai prosedur pengembangan yang akan digunakan:

1. Tahap Analisis

Berdasarkan tahap analisis yang dilakuakan peneliti dengan melakukan wawancara Guru Biologi di MA Mu'allimin NW anjani, media pembelajaran yang digunakan kurang variatif yaitu hanya media cetak berupa buku teks dan LKS saja sehingga membuat peserta didik kurang bersemangat saat pembelajaran berlangsung.

2. Tahap Desain ( Design)

Pada tahap ini peneliti akan merancang produk yang akan dibuat pada media pembelajaran. Rancangan ini tentu memiliki tahapan-tahapan yang akan dilalui. Pada tahap desaign akan dilakukan 4 kegiatan yaitu : constructing critetion-referenced tes, media selection, format selection, initial design.

3. Tahap pengembangan (Development)

Pada tahap pengembangan ini, ada 3 langkah yang akan dilakukan yaitu:

a) Membuat angket validitas produk untuk ahli media dan ahli materi, angket untuk respon guru dan peserta didik.

b) Validasi desain media pembelajaran yang dilakukan oleh ahli media dan ahli materi. Tujuan dilakukan validasi untuk mendapatkan penilain dan saran dari ahli materi serta ahli media mengenai kesesuaian materi dan tampilan media.

c) Setelah mendapat masukkan dari para ahli dan divalidasi, maka diketahui kelemahannya. Kelemahan tersebut selanjutnya diperbaiki atau direvisi. 
Teknik pengumpulan data dengan observasi, wawancara, angket dan dokumentasi. Teknik analisis data mengacu pada skala Likert. Persentase kelayakan media pembelajaran dihitung dari 4 (empat) macam evaluator. yakni ahli materi, ahli media, guru mata pelajaran dan siswa atau peserta didik sebagai responden. Penghitungan persentase kelayakan media pembelajaran menggunakan rumus sebagai berikut:

\section{Rumus: Persentase kelayakan (\%) =Skor yang diperoleh $x 100 \%$ \\ Skor yang diharapkan}

(Sugiyono, 2009)

Selanjutnya data persentase yang diperoleh kemudian dikonversikan menggunakan kriteria validitas yang mengacu pada Tabel 1.

Tabel 1. Kriteria Validasi Media Pembelajaran Multimedia Interaktif Berbasis SAVI

\begin{tabular}{|c|c|}
\hline Skor Persentase & Kriteria \\
\hline $82 \%-100 \%$ & Sangat Baik \\
\hline $63 \%-81 \%$ & Baik \\
\hline $44 \%-62 \%$ & Kurang Baik \\
\hline $25 \%-43 \%$ & Tidak Baik \\
\hline $0 \%-24 \%$ & Sangat Tidak Baik \\
\hline
\end{tabular}

\section{HASIL DAN PEMBAHASAN}

\subsection{Hasil Penelitian}

Hasil pengembangan media interaktif yang telah dikembangkan memiliki beberapa item yaitu : Halaman pembuka, menu media pembelajaran, menu peta konsep, menu materi, menu Quiz, menu video, menu rangkuman. Berikut tampilan item-item tersebut.

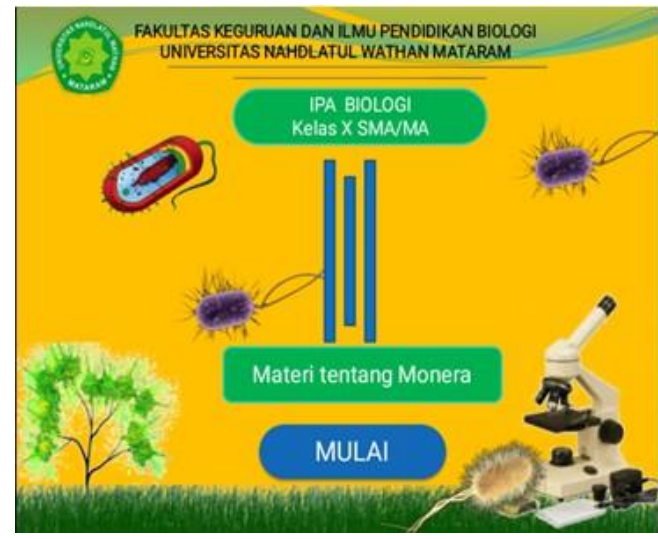

1. Halaman Pembuka

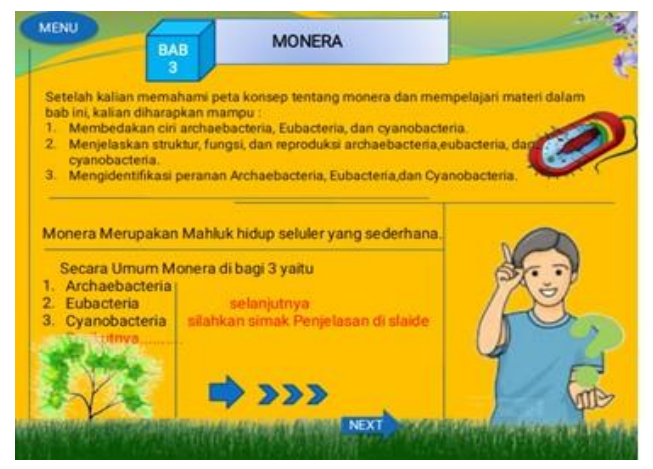

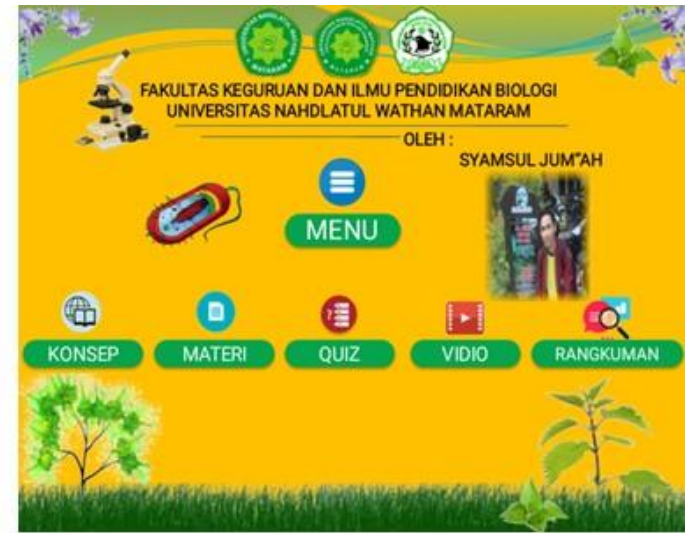

2. Menu Media Pembelajaran

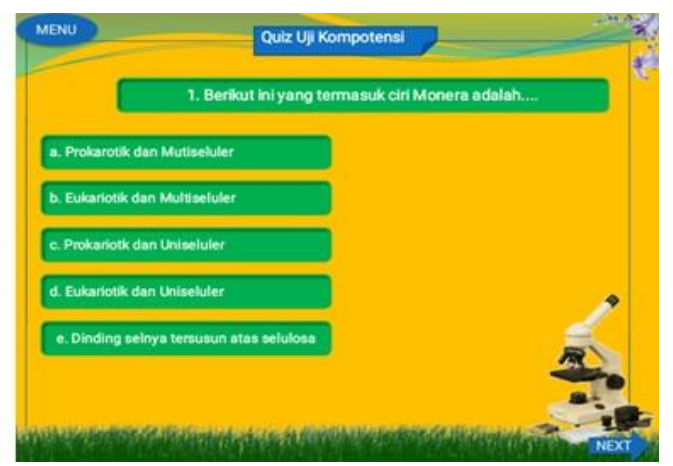


3. Menu Peta Konsep

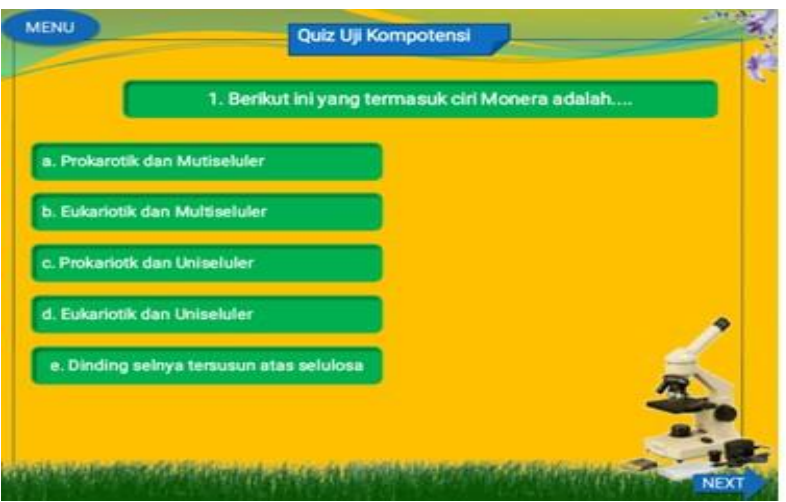

5. Menu Quiz
4. Menu Materi

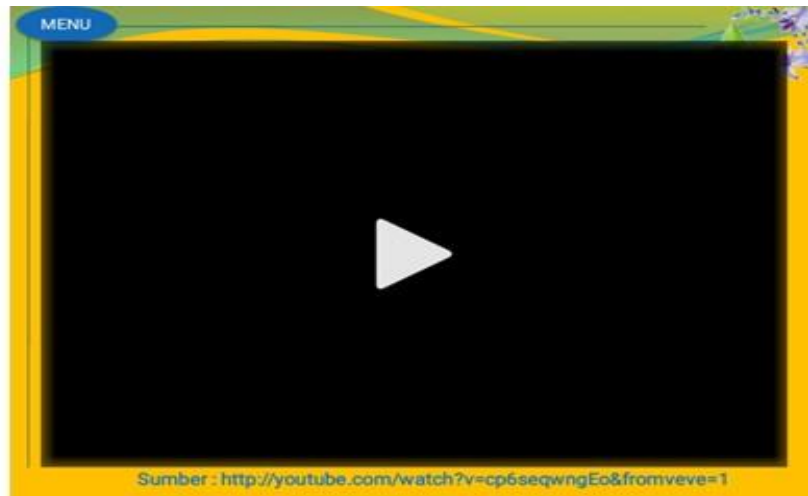

6. Menu Video

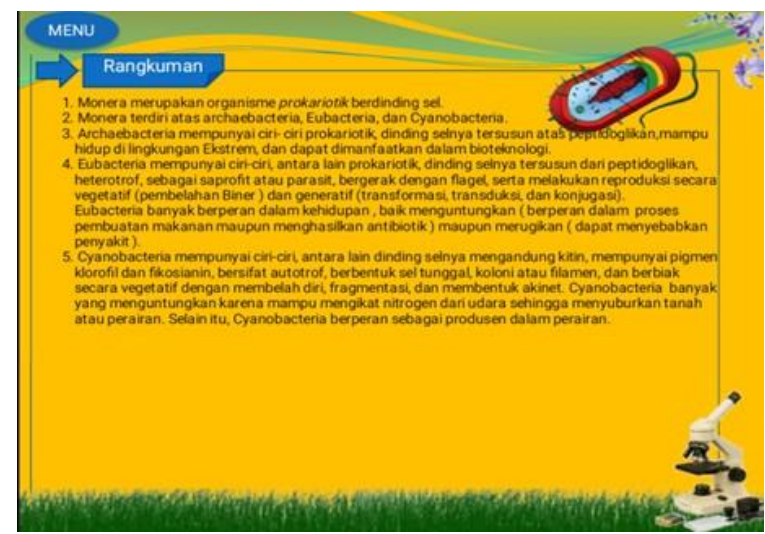

7. Menu Rangkuman

Media pembelajaran yang telah dikembangkan kemudian divalidasi oleh ahli media dan ahli materi. Validator media adalah bapak Hanafi, M.Pd. Beliau adalah dosen program studi pendidikan Biologi, FKIP, UNW MATARAM. Validasi media pembelajaran oleh ahli media bertujuan untuk mengetahui pendapat ahli media sebagai dasar dalam memperbaiki dan meningkatkan kualitas media pembelajaran. Hasil validasi ahli media disajikan pada Gambar 2.

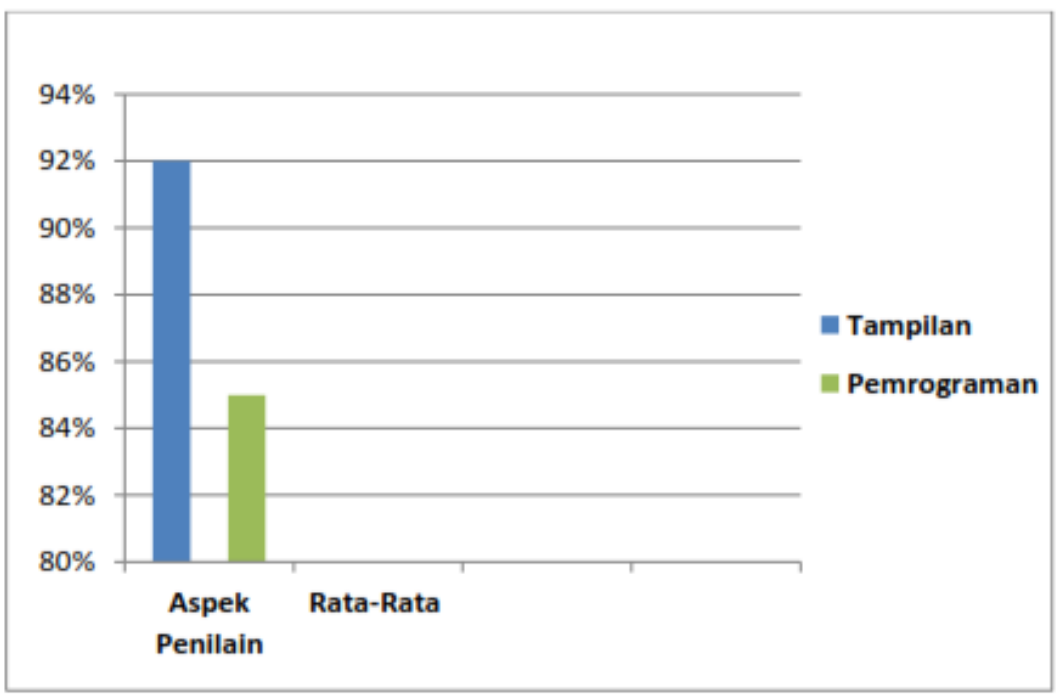

Gambar 2. Penilaian Ahli Media 
Berdasarkan Gambar 2, dapat diketahui bahwa penilaian media pembelajaran dilihat dari dua aspek yaitu aspek tampilan dan pemrograman. Aspek tampilan mendapatkan persentase sebesar 92\%, sedangkan aspek pemrograman mendapatkan persentase sebesar $85 \%$. Rata-rata total penilaian ahli media adalah sebesar $85,5 \%$. Persentase ini termasuk kriteria layak sebagai media pembelajaran.

Validator materi adalah Bapak Rustam, M.Pd selaku adalah Pembimbing akademik Pendidikan Biologi sekaligus Dosen UNW Mataram. Validasi media pembelajaran oleh ahli materi bertujuan untuk mengetahui pendapat ahli materi sebagai dasar dalam memperbaiki dan meningkatkan kualitas media pembelajaran. Hasil validasi ahli materi disajikan pada Gambar 3.

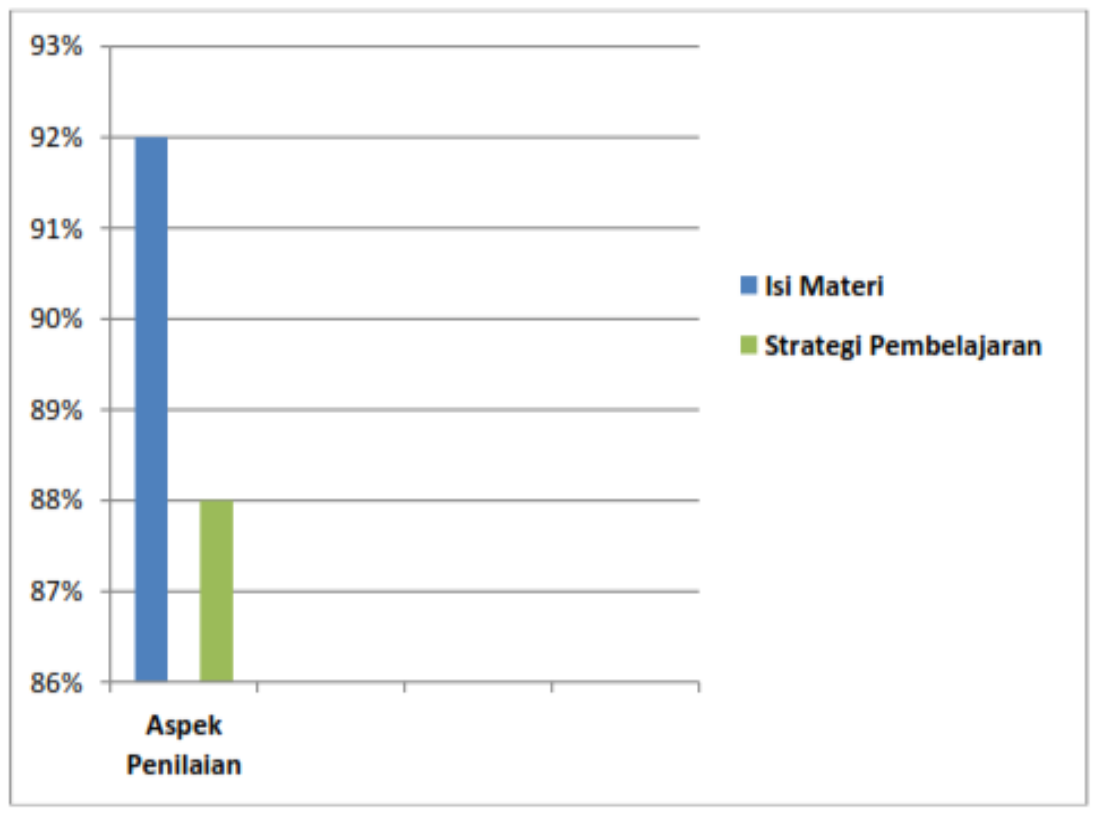

Gambar 3. Penilaian Ahli Materi

Dari Gambar 3, dapat diketahui bahwa penilaian ahli materi terhadap media pembelajaran dapat dilihat dari dua aspek yaitu isi materi dan strategi pembelajaran. Dilihat dari aspek isi materi, persentasenya adalah sebesar 92\%. Dilihat dari aspek strategi pembelajaran, persentasenya adalah sebesar $88 \%$. Rata-rata total penilaian ahli materi adalah sebesar $90 \%$ dan termasuk kriteria layak digunakan sebagai media pembelajaran.

\subsection{Pembahasan}

Penggunaan media sangat diperlukan untuk mendukung keberlangsungan pembelajaran IPA khususnya pada Materi Monera dan materi-materi lain pada umumnya. Media pembelajaraan yang dapat digunakan dalam pembelajaran IPA salah satunya adalah Multimedia Interaktif Biologi berbasis SAVI yang dirancang untuk menjadikan suasana belajar menjadi lebih menyenangkan. Hal ini karena setiap siswa dapat mengoperasikan media secara mandiri sehingga penggunaannya menyesuaikan dengan kemampuan akademik masing-masing siswa.

Model pembelajaran SAVI merupakan suatu model pembelajaran yang menggabungkan gerak fisik dengan aktivitas intelektual dan penggunaan semua indranya dalam proses pembelajaran (Sihwinedar, 2015). Pengembangan media pembelajaran multimedia interaktif berbasis SAVI pada materi monera yang telah dilakukan, dinyatakan layak untuk dijadikan sebagai media pembelajaran di dalam proses pembelajaran. Hal ini berdasarkan hasil validasi yang telah di lakukan, yaitu validasi ahli media dengan persentase 8,5 
$\%$, dan ahli meteri dengan persentase $90 \%$. Dalam penelitian hanya sampai tahap validasi dikarenakan pada kondisi Covid-19 sekarang ini tidak memungkinkan untuk dilakukannya uji lapangan kepada siswa.

Multimedia interaktif yang sudah dibuat memiliki kualitas gambar, video dan tulisan yang sudah cukup baik sehingga siswa merasa lebih semangat dalam belajar menggunakan. Menurut Muhson (2010), manfaat media dalam proses pembelajaran adalah memperlancar interaksi antara guru dan siswa sehingga kegiatan pembelajaran akan lebih mudah dipahami

\section{SIMPULAN}

Berdasarkan hasil penelitian dan pembahasan yang telah dituliskan pada bab sebelumnya dapat disimpulkan sebagai berikut :

1. Kualitas Multimedia Interaktif biologi berbasis Savi dapat dilihat dari penelian tim ahli validasi yaitu dosen ahli media dan dosen ahli materi.

2. Penilaian ahli media berdasarkn tampilan mendapatkan persentase sebesar $92 \%$, sedangkan penilaian berdasakan pemrograman mendapatkan persentase sebesar $85 \%$. Sehinga rata-rata penilaian ahli media terhadap keseluruhan aspek mendapatlkan persentase $90 \%$ termasuk dalam kategori layak.

3. Penilaian ahli materi berdasarkan isi materi mendapatkan persentase sebesar $92 \%$, sedangkan penilain berdasarkan strategi pembelajaran mendapatkan persentase sebesar $88 \%$. Sehingga rata-rata penilaian ahli materi terhadap keseluruhan aspek mendapatkan persentase $90 \%$ termasuk dalam kategori layak.

\section{DAFTAR PUSTAKA}

Muhson, Ali. 2010. Pengembangan Media Pembelajaran Berbasis Teknologi Informasi. Jurnal Pendidikan Akuntansi Indonesia, Vol. VIII. No. 2

Sihwinedar, Rinendah. 2015. Meningkatkan Hasil Belajar IPA Melalui Penerapan Model Pembelajaran SAVI ( somatic auditory, visual, dan intlektual) Pada Siswa Kelas III SDN Rejoagung 01 Semboro Tahun Pelajaran 2013/2014. Forum Penelitian, 4(4), 137-148

Sugiyono. 2009. Statistik Untuk Penelitian. Bandung: Alfabeta.

Susilana, Rudi \& Riana, Cepi. 2009. Media Pembelajaran Hakikat, Pengembangan, Pemammfaatan dan Penilaian. Bandung: CV Wacana Prima

Wijaya, Hadi. 2016. Pengembangan Bahan Ajar Biologi Berbasis Pendekatan Savi Pada Sub Pokok Bahasan Ekosistem Kelas VII SMP. Skripsi. Jember: Fakultas keguruan dan ilmu pendidikan Biologi Universitas Jember. 